\title{
Gradhiva
}

GRADHIV

Revue d'anthropologie et d'histoire des arts

16 | 2012

Chines, l'État au musée

\section{Barrage des Trois-Gorges : exposer le monde local après l'immersion. Genèse et programme du premier musée de Yunyang}

The Three Gorges Dam : Exhibiting Post-Diluvian Local Worlds. The Creation of Yunyang's First Museum and its Exhibition Programme

\section{Katiana Le Mentec}

\section{OpenEdition}

\section{Journals}

Édition électronique

URL : http://journals.openedition.org/gradhiva/2469

DOI : $10.4000 /$ gradhiva.2469

ISSN : 1760-849x

Éditeur

Musée du quai Branly Jacques Chirac

Édition imprimée

Date de publication : 1 décembre 2012

Pagination : 84-105

ISBN : 978-2-35744-048-7

ISSN : 0764-8928

\section{Référence électronique}

Katiana Le Mentec, «Barrage des Trois-Gorges : exposer le monde local après l'immersion. Genèse et programme du premier musée de Yunyang », Gradhiva [En ligne], 16 | 2012, mis en ligne le 01

décembre 2015, consulté le 01 mai 2019. URL : http://journals.openedition.org/gradhiva/2469 ; DOI : 10.4000/gradhiva.2469 


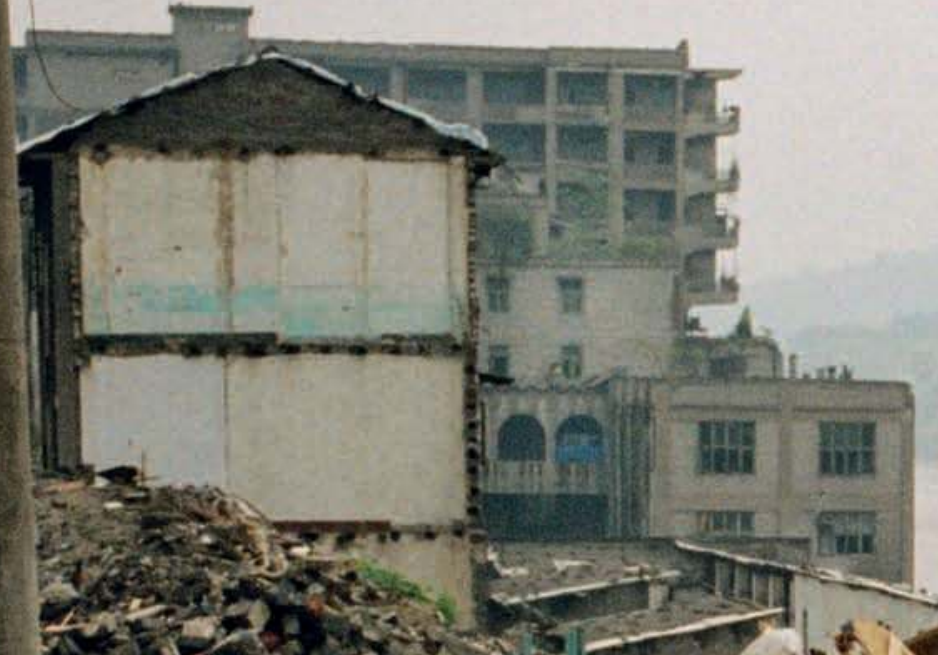

$x^{-\infty}$

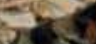

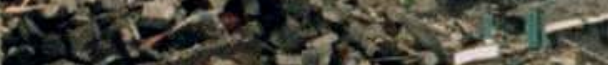

3 - noserans.

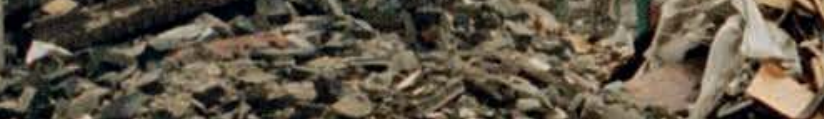
pis

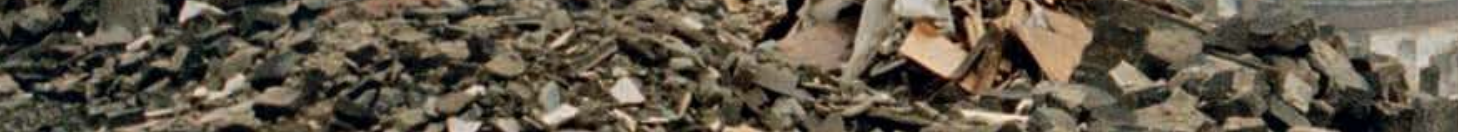

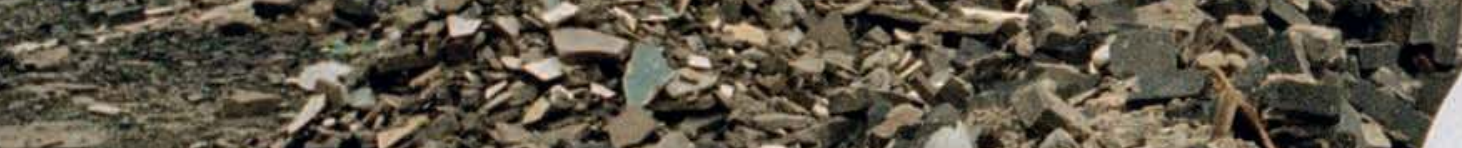

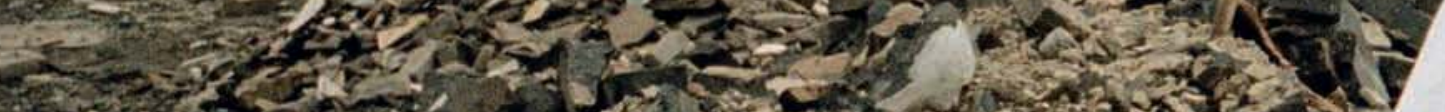

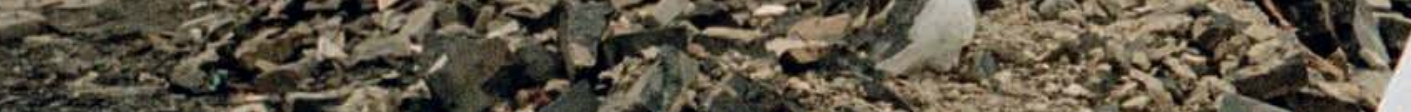

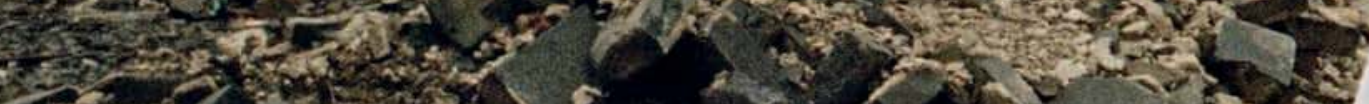

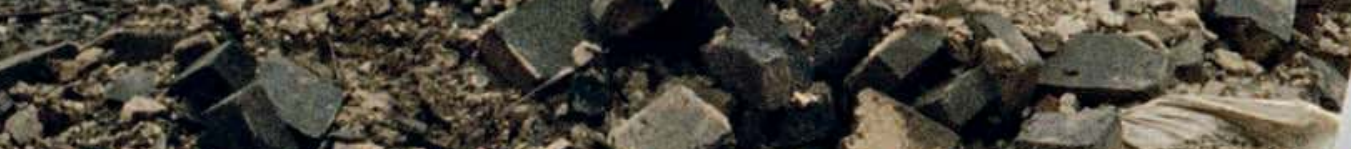

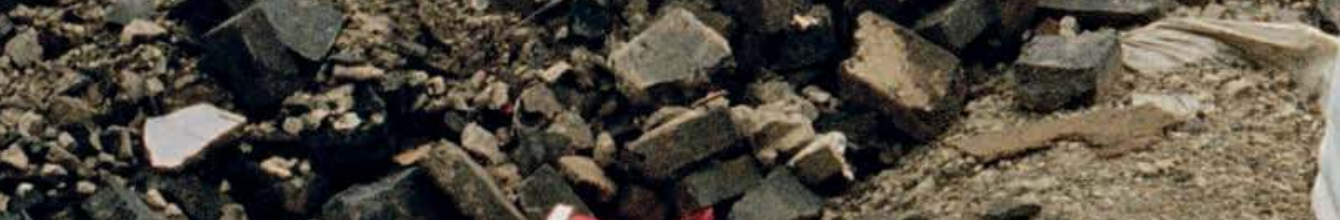
- $\div$ - Jus

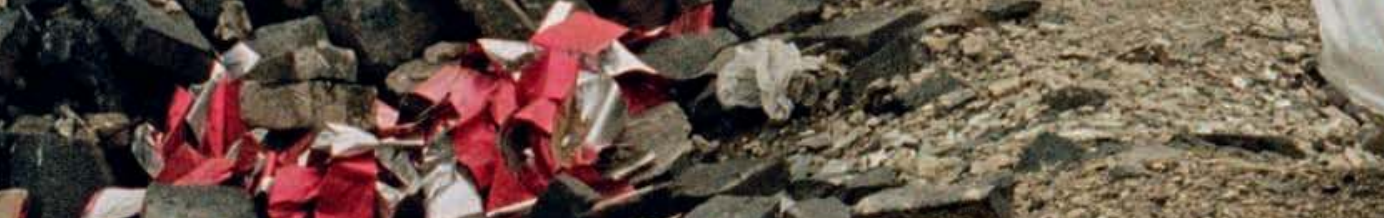
7 - त

$\rightarrow$

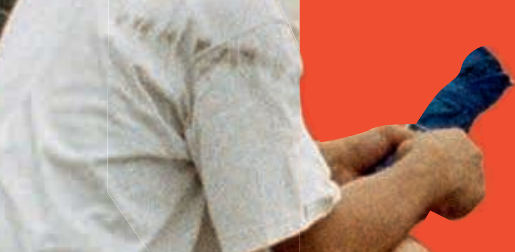

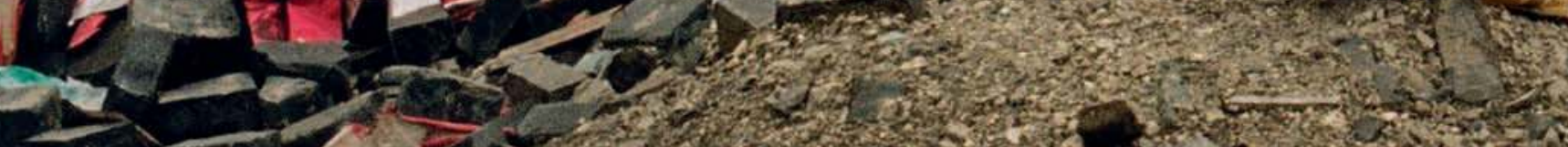

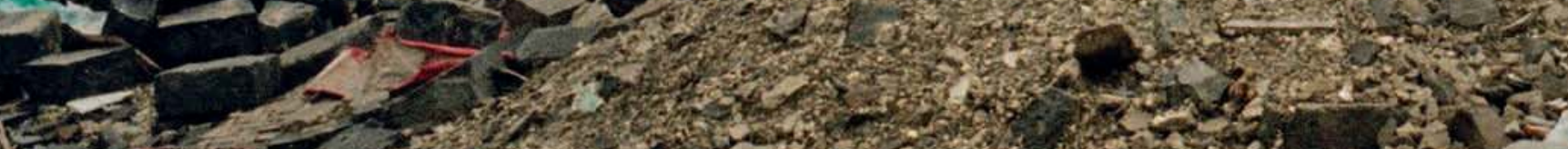
15

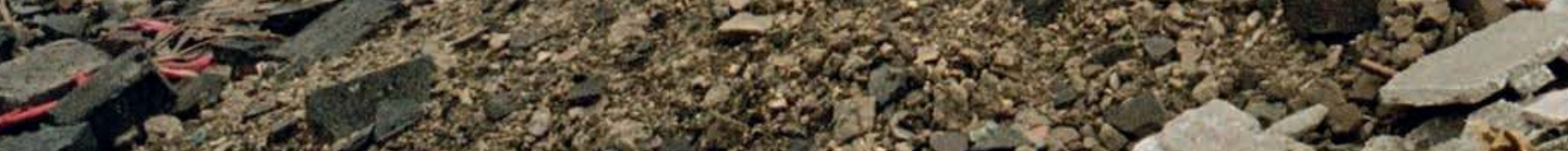

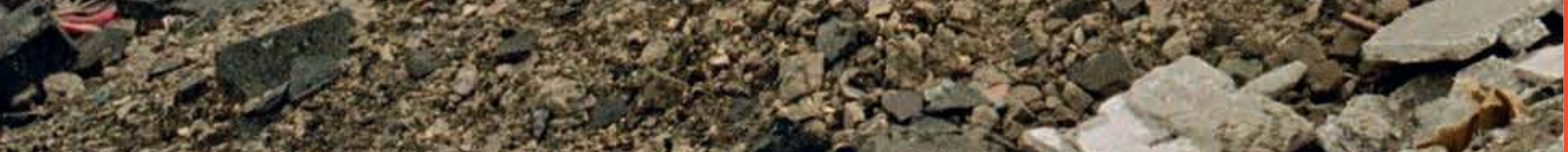

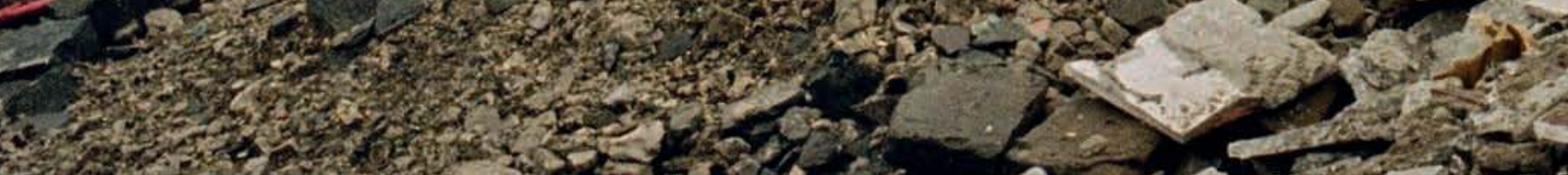
6. 


\section{Barrage des Trois-Gorges: exposer le monde local après l'immersion}

Genèse et programme du premier musée de Yunyang

par Katiana Le Mentec

La création du barrage des Trois-Gorges

a entraîné dans le district de Yunyang

(Chongqing) de profondes transformations du paysage, le déplacement d'une partie de la population et la reconstruction de villes.

Le gouvernement local a élaboré au fil des ans des projets muséographiques visant à exposer ces processus. Cet article met en regard deux initiatives, dont l'une est en cours de réalisation. II présente la genèse de ces projets et compare leur programme en considérant le rôle des personnalités politiques.

Le sens attribué à leur architecture est analysé comme l'élément révélateur de la manière dont les autorités locales cherchent à situer le district après les bouleversements.

L'article se poursuit par l'analyse de deux nouveaux concepts développés par les autorités locales dans le but de légitimer le déplacement forcé et de commémorer l'esprit patriotique des habitants. La conclusion porte sur la présence de l'écologie régionale dans ces institutions culturelles et sur la volonté des autorités de présenter un monde local unissant le passé au présent. 


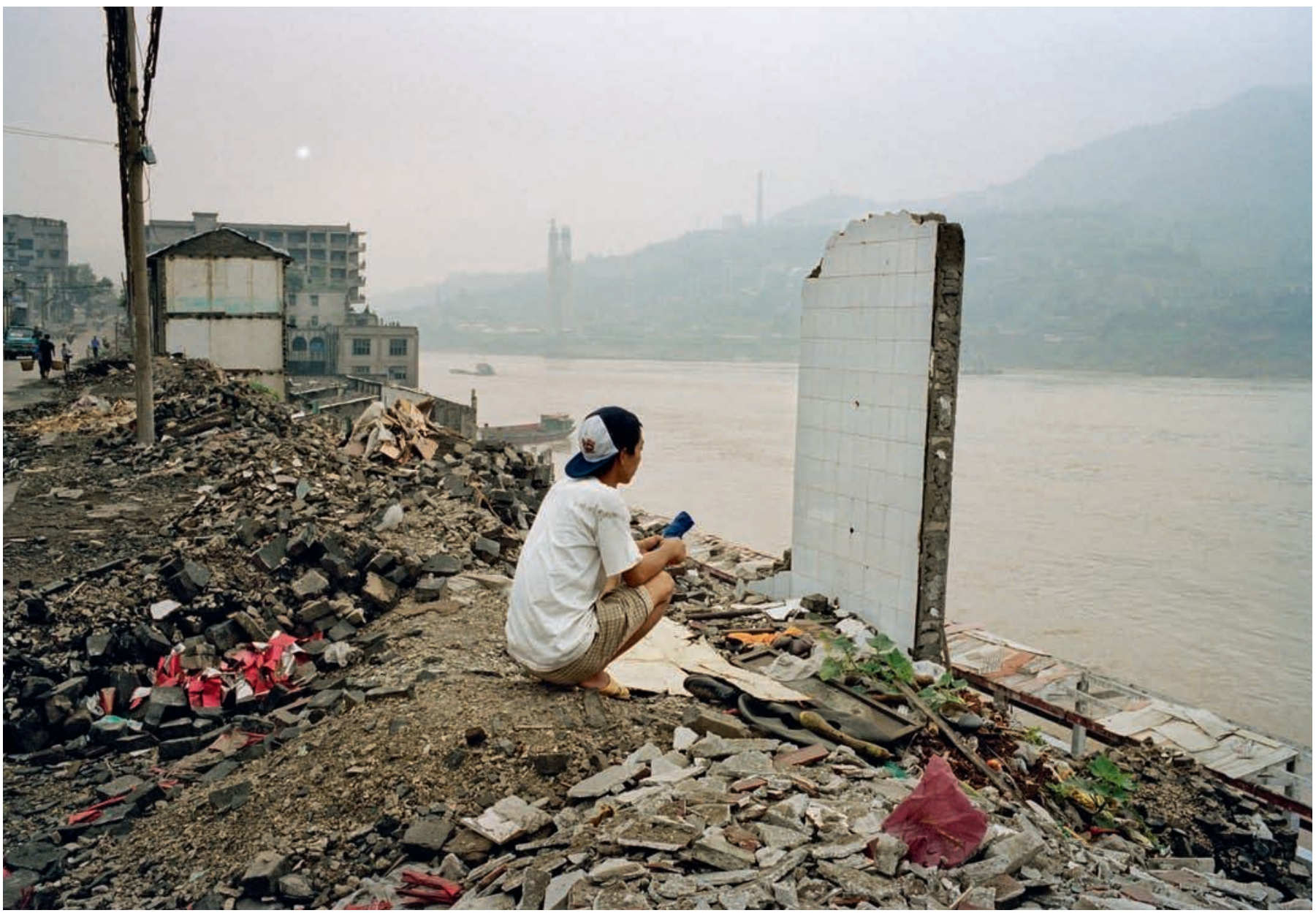

page précédente et ci-dessus

fig. 1

Au bord du Yangzi Jiang, avant l'immersion de la ville de Wanzhou (Chongqing), 2002 (C) Ian Berry/Magnum Photos.
Plusieurs années se sont écoulées depuis l'achèvement du gigantesque barrage construit en aval des Trois-Gorges du Yangzi Jiang. L'élévation du niveau du fleuve entre 2003 et 2009 a entraîné la transformation du paysage, la reconstruction de dizaines de villes et de centaines de villages ainsi que le déplacement de près de 2 millions de personnes. Dans le district rural et montagneux de Yunyang (municipalité de Chongqing), près de 140000 personnes ont été déplacées (soit un dixième de la population) et le chef-lieu a été entièrement délocalisé. Ces processus n'étaient pas encore achevés que le gouvernement local prévoyait déjà de les mettre en exposition au sein d'un vaste parc muséographique dédié au «yimin des Trois-Gorges» (三峽移民, sanxia yimin). Cette expression désigne à la fois le processus de déplacement, le travail de délocalisation, les instances administratives chargées de son bon déroulement et les personnes déplacées en raison du barrage des Trois-Gorges ${ }^{1}$. À Yunyang, le yimin des Trois-Gorges fut choisi comme nouvelle «marque» locale. Le projet de parc muséographique qui lui est dédié, conçu à partir de 2003 sous l'impulsion d'un nouveau gouverneur local, s'intégrait dans le cadre d'une politique nationale et régionale encourageant les administrations locales à fonder des musées. C'est finalement une autre proposition muséale, de moindre envergure et portée par une autre figure politique locale, qui verra le jour en 2012. 
Je propose de retracer la genèse de ces projets muséaux et d'analyser le contenu de leurs programmes respectifs au regard de l'évolution du contexte et du rôle joué par les personnalités politiques. Après avoir présenté ces dirigeants, leurs motivations et leur projet, j'envisagerai l'architecture qu'ils ont choisie comme élément révélateur de la manière dont ils considèrent Yunyang après les bouleversements. Le premier d'entre eux insiste sur l'appartenance de ce district à la municipalité de Chongqing récemment créée, tandis que le second porte l'emphase sur son intégration à la Chine. J'analyserai ensuite, à travers l'étude de deux nouveaux concepts diffusés par les autorités locales, la façon dont les projets muséaux de ces dirigeants prévoient de présenter le yimin des Trois-Gorges. L'invention de la «culture du yimin » leur permet à la fois de dédramatiser et de légitimer le déplacement, présenté comme une tradition régionale. La notion d'«esprit du yimin " leur sert quant à elle tant à présenter les personnes déplacées comme des patriotes qu'à glorifier un ensemble de vertus commémorées dans ces institutions muséales. En conclusion, j'évoquerai la tentative commune à ces projets d'unir le passé au présent et de présenter l'écologie régionale comme enrichie. Cet article vise à donner un aperçu des choix effectués par les officiels de Yunyang pour exposer le monde local après l'immersion ${ }^{2}$.

\section{Des dirigeants locaux et de leurs initiatives culturelles}

Xiao Min est né en 1956 dans le district de Fengjie, voisin de celui de Yunyang. Issu d'une famille modeste, il a suivi une formation de vétérinaire dans une école professionnelle agricole locale. Une fois diplômé, il est entré dans la fonction publique et s'est engagé au Parti communiste. C'était l'époque de l'arrivée de Deng Xiaoping au pouvoir et du lancement des réformes économiques. À Fengjie, Xiao Min gravit rapidement les échelons de l'administration locale et assuma des fonctions de direction, tant au sein du gouvernement que du Parti communiste ${ }^{3}$. En 1992, il fut nommé secrétaire adjoint du Parti communiste du district de Fengjie, puis du district de Yunyang cinq ans plus tard, avant d'être élu en 2002, à 46 ans, gouverneur de Yunyang. Il a occupé cette fonction pendant quatre ans. II intervenait régulièrement sur la chaîne de télévision locale et lors des fêtes officielles, et ses propos étaient retranscrits chaque semaine dans le journal local. Li Shihu, historien local, le connaît bien et en fait l'éloge, le qualifiant d'«homme de culture». Dans le district, cette étiquette lui est donnée par des fonctionnaires et parfois par des habitants. C'est également de cette manière que Xiao Min s'est présenté lors de notre rencontre en 20114 . II souligna son adhésion à l'Association nationale des écrivains et montra ses recueils de poèmes. En Chine, de nombreux fonctionnaires s'adonnent à la poésie. Xiao Min et Li Shihu font partie de la même association culturelle régionale et participent aux conférences qu'elle organise ainsi qu'à la revue qu'elle édite. Dans ce cadre, Xiao Min a rédigé des articles portant sur I'histoire et la culture locales dont nous avons longuement discuté. II est aujourd'hui inspecteur général adjoint du bureau de la culture, de la radio et de la télévision de la municipalité autonome de Chongqing. II a été nommé à ce poste - l'un des plus prestigieux du gouvernement régional - en 2007. Son domaine de juridiction porte sur les programmes de protection des vestiges ainsi que sur le musée des Trois-Gorges, créé par la municipalité. La reconnaissance dont il a bénéficié de la part de la hiérarchie adminis-
1. Dans les années 1950 , le gouvernement chinois constitua une catégorie administrative, le «yimin réservoir », pour rendre compte des déplacements de population induits par la création de réservoirs d'eau. En raison de l'ampleur du processus provoqué par le barrage dit des Trois-Gorges, les autorités créèrent la catégorie «yimin des Trois-Gorges ».

Dans la langue chinoise, le terme yimin, à la fois verbe et substantif, qualifie aussi bien les mouvements de population que les individus qui se déplacent. Min signifie "peuple " et yi implique

l'action de bouger.

2. Ce travail fait suite à une thèse d'ethnologie portant sur les registres interprétatifs et les formes de résilience développés par les habitants et les autorités de Yunyang pour appréhende les bouleversements et faire face au contexte de rupture (Le Mentec 2011). Un terrain effectué à l'automne 2011 dans la municipalité de Chongqing a permis de recueillir des informations pour un nouveau projet de recherche portant sur les musées en construction dans la région.

'ethnographie a été élaborée à partir d'observations, de discussions et d'entretiens informels ou formels (et dans ce cas non directifs).

D'autres sources ont été sollicitées, tels les archives locales, les médias, les sites internet officiels, les ouvrages publiés localement ou encore des documents officiels internes de travail qui m'ont été transmis par des fonctionnaires du bureau de la culture que j'ai été amenée à rencontrer régulièrement au fil des ans.
3. En Chine, à tous les niveaux de la hiérarchie, les circonscriptions administratives sont à la fois dirigées par une équipe gouvernementale (dont les membres sont élus par une assemblée) et une équipe du Parti communiste (dont les membres sont nommés en interne)

4. En expliquant mon projet d'écrire un article sur les musées de Chongqing j'avais sollicité le directeur adjoint du musée des TroisGorges pour un entretien. Il m'ouvrit les portes du centre de recherche attache au musée et proposa à son responsable, Xiao Min, de me rencontrer. Celui-ci avait déjà entendu parler de mes travaux sur le patrimoine local de Yunyang par Li Shihu et des membres du bureau de la culture. II accepta de me recevoir sur son lieu de travail. 
5. Il est commun en Chine que des fonctionnaires condamnés en justice retrouvent un poste dans l'administration. Toutefois, la promotion dont Xiao Min a bénéficié témoigne de l'important réseau qu'il s'était constitué et sans doute de l'intérêt des dirigeants de Chongqing pour ses initiatives culturelles.

6. Sur le parc muséographique, voir Zhou (2004), Li (2006) et SOY (2008). La nouvelle fête a été analysée précédemment (Le Mentec 2011).

7. Le lieu dit des Trois-Gorges correspond à l'espace bordant le Yangzi Jiang à l'est de Chongqing.

8. Cette somme correspond à environ 25 millions d'euros. trative régionale ne semble pas refléter le bilan économique de son mandat à la tête du district de Yunyang, qu'une partie de la population désapprouve; des fonctionnaires osent aujourd'hui le critiquer ouvertement: «C'est un homme de culture, il ne connaît rien à l'économie, il n'a rien fait pour notre district! " s'est permis de dire un ancien membre du bureau de la culture lors d'une conversation informelle à l'automne 2011.

Avant même la montée des eaux, Yunyang était considéré comme l'un des districts les plus pauvres de Chine. Il est situé au cœur d'une région montagneuse surpeuplée, faiblement industrialisée, accueillant peu d'entreprises privées et accusant un fort taux d'illettrisme. Compte tenu de la faible valeur foncière des terrains, les fonds octroyés aux autorités locales pour la reconstruction des infrastructures urbaines et le relogement des familles n'ont pas été aussi conséquents que dans les autres districts touchés par la montée des eaux. Le manque d'investissements et d'industries est patent et le district ne pourrait survivre sans les aides financières de l'État, envers lequel il s'est considérablement endetté (Nanfengchuang 2006). L'inflation des prix et de l'immobilier à Yunyang ces dernières années ternit le constat positif des chiffres officiels mettant en avant une augmentation du revenu moyen local. Comme dans bien d'autres territoires en Chine, les habitants dénoncent souvent la corruption et le gaspillage de l'argent public, considérés comme des freins au développement et à l'enrichissement de la population. À la fin de son mandat à Yunyang, Xiao Min fut condamné à six mois de prison pour détournement de fonds. Son image publique s'est dégradée à la suite de cette affaire, largement commentée à l'époque par les habitants et encore très présente dans les esprits, comme j'ai pu le constater en 2011.

La promotion dont Xiao Min a bénéficié au sein du gouvernement régional, après avoir purgé sa peine, est probablement liée aux mesures qu'il a prises en matière de politique culturelle à Yunyang et aux concepts de «culture du yimin» et «d'esprit du yimin» qu'il a inventés, aujourd'hui très largement investis par les autorités municipales ${ }^{5}$. Dès son élection en tant que gouverneur du district, Xiao Min a entrepris deux projets culturels: un parc muséographique et une fête locale, tous deux dédiés au yimin des Trois-Gorges ${ }^{6}$. Ceux-ci ont pris forme au fil de réunions et d'ateliers de réflexion réunissant des membres des bureaux de la culture au niveau local et régional. La fête fut inaugurée sous une forme encore balbutiante en 2003, époque à laquelle on installa les premiers éléments sur les lieux du futur parc muséographique. Ce dernier, couvrant une surface de 53 hectares, devait être installé au pied de la colline du nouveau cheflieu, à la pointe est du parc aménagé le long de la berge du Yangzi Jiang.

Lorsque le projet reçut en 2005 l'approbation officielle de la Commission d'État au développement et aux réformes, son programme était déjà médiatisé depuis quelques années. II s'agissait avant tout de «commémorer» (紀念, jinian) le yimin, mais d'autres thèmes y étaient attachés. La culture régionale et l'écologie des Trois-Gorges 7 constituaient deux autres axes thématiques importants, qui témoignaient d'une vaste ambition pour un district rural n'ayant jamais accueilli de musée. Le parc muséographique constituait l'un des projets touristiques phares du programme de 


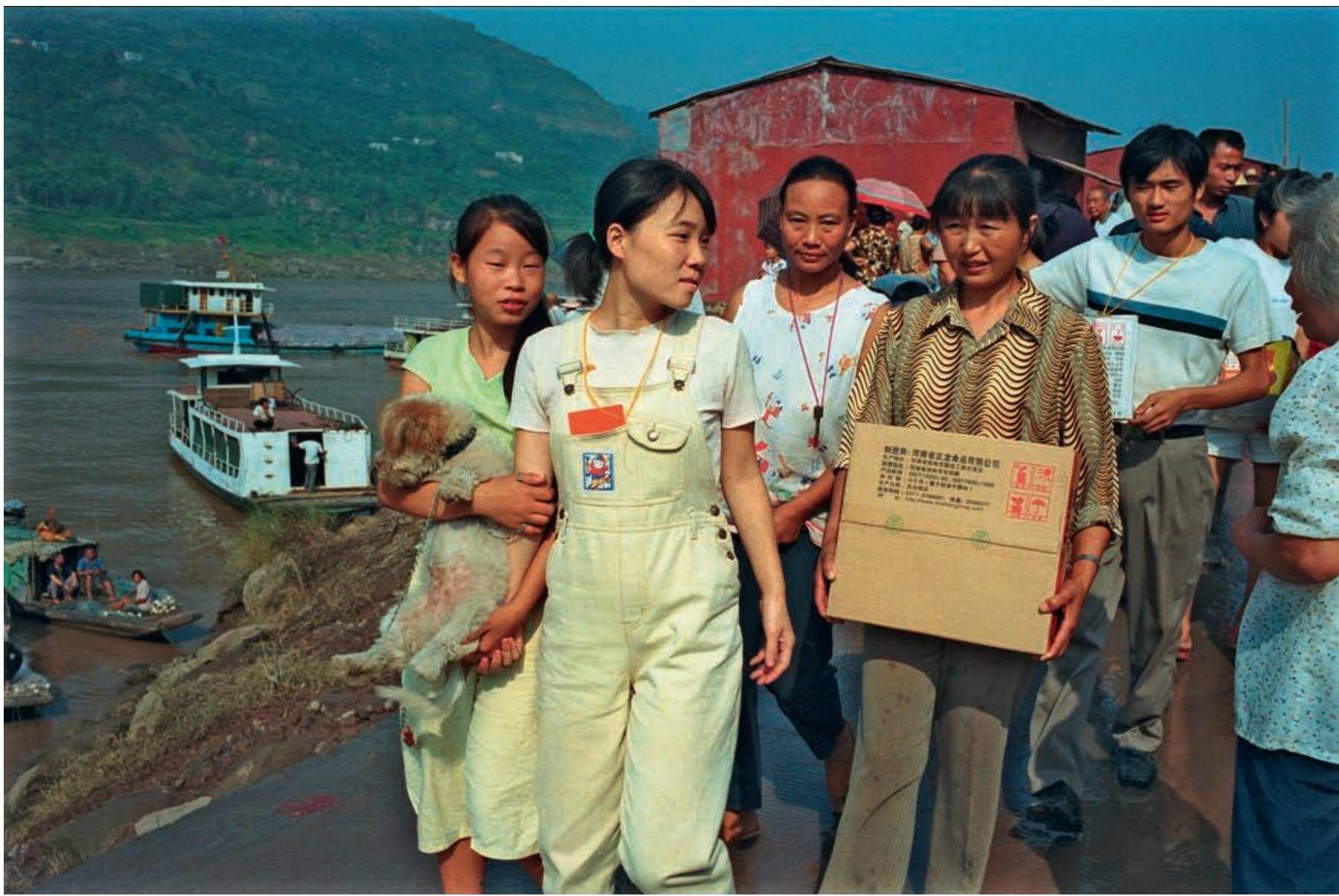

développement local. L'objectif était d'attirer vers le nouveau chef-lieu les habitants de la région, mais surtout les touristes qui traversent chaque jour par centaines les Trois-Gorges sur des bateaux de croisière, peu nombreux pourtant à séjourner à Yunyang. Le gouvernement local prévoyait d'investir un sixième du budget nécessaire à la réalisation du parc, s'élevant à 200 millions de yuans ${ }^{8}$.

En 2009, après plusieurs années de recherche de financements privés, le projet fut définitivement abandonné. Lors de notre conversation, Xiao Min a évoqué avec regret cette situation en retraçant les nombreuses années durant lesquelles il a œuvré pour sa réalisation. D'après lui, le manque de moyens n'est qu'une des causes de cet échec. Le gouvernement de Wanzhou, district voisin de Yunyang, s'est lancé dans l'élaboration d'un musée commémoratif du yimin des Trois-Gorges dont le programme d'exposition est très similaire au projet original de Yunyang. Bien plus riche que ce dernier, Wanzhou a pu réunir les fonds pour construire le bâtiment dont l'aménagement a débuté en 2012. Pour Xiao Min, l'abandon de «son» idée s'explique aussi par le manque d'intérêt de la nouvelle équipe gouvernementale de Yunyang, qui s'est consacrée au développement d'autres initiatives touristiques et culturelles. L'arrêt du projet de parc muséographique est concomitant de l'éviction du concept «yimin des Trois-Gorges» en tant que thème principal de la fête que Xiao Min avait instaurée. D'après fig. 2

Famille de déplacés quittant Yunyang (Chongqing) avant son immersion, 2002 (c) Ian Berry/Magnum Photos. 


\section{double page \\ précédente}

fig. 3

Fengjie \#6, préparation de l'immersion des berges du fleuve Yangzi en amont du barrage des Trois-Gorges, 2002 C Edward Burtynsky. des membres du bureau local de la culture rencontrés en 2011, ces changements sont directement liés à la nomination d'un nouveau secrétaire du Parti communiste: Li Hongyi.

Li Hongyi est originaire du Shandong, province riche et urbanisée bordant la côte nord-est de la Chine. Il est entré dans la fonction publique après une formation en comptabilité. II a intégré le bureau provincial des finances en 1993 avant d'être nommé, en 2002, secrétaire du Parti communiste et gouverneur adjoint d'une ville de cette province. II a ensuite été engagé dans le programme de jumelage liant le district de Yunyang et la province du Shandong, qui prévoit notamment l'échange de fonctionnaires entre les deux administrations. En 2008, Li Hongyi fut ainsi nommé secrétaire du Parti communiste de Yunyang aux côtés du nouveau gouverneur, Teng Yingming. Lors de conversations informelles, j'ai pu constater que certains habitants se félicitaient de cette nomination. Ils perçoivent Li Hongyi, venant d'une région économiquement plus développée, comme un fonctionnaire possédant les compétences nécessaires au développement local. Tout comme Xiao Min lors de son arrivée à la direction de Yunyang, ce nouveau secrétaire du Parti lança de grands chantiers culturels. Pour ce dernier, étranger à la région, il s'agissait d'asseoir son autorité mais aussi d'apposer «sa» marque dans le district. II n'était donc pas question de reprendre un ancien projet, connaissant des difficultés depuis plusieurs années et compromis par la réputation de son créateur.

Li Hongyi propose son propre projet: une promenade dite écologique, aménagée le long de la crête de la colline du nouveau chef-lieu, et, à son extrémité ouest, un centre d'activités culturelles rassemblant une bibliothèque, un théâtre, un cinéma, une maison des jeunes, une salle d'expositions, un palais de la culture, une annexe des bureaux de la culture et de la propagande, une salle de conférences ainsi que le premier musée du district. Le projet architectural du complexe culturel a été sélectionné en 2009. Le bâtiment comprend cinq niveaux, couvrant une superficie totale de 30000 mètres carrés, et son budget s'élève à 100 millions de yuans 9 . L'appel d'offres pour l'aménagement intérieur a été lancé l'année suivante. Plusieurs entreprises privées ont travaillé avec le soutien logistique des bureaux de la culture et de la propagande du district. Le gouvernement local a recruté une entreprise privée spécialisée dans la réalisation scénographique d'expositions culturelles, dont le siège est basé dans le Sichuan. Li Hongyi a également fait appel à une entreprise du Shandong avec laquelle il était en relation. Les travaux ont débuté en 2010, une fois l'ensemble des financements (publics et privés) recueilli. Ce centre culturel est présenté comme la «nouvelle marque locale» (新地标, xin dibiao) [SOY 2012a].

En 2011, le directeur du bureau de la culture, Li Jianjun, me présenta ce projet muséal ${ }^{10}$. II me transmit le programme préliminaire complet, alors en cours de validation par l'administration régionale - le bureau de la culture de Chongqing et un comité de chercheurs du musée des Trois-Gorges (sous la supervision de Xiao Min). Le projet du centre culturel est médiatisé depuis quelques années. Une vidéo de présentation, réalisée par l'entreprise d'architecture Tanghua Studio (2011) de Shenzhen, dont le dirigeant est originaire de Chongqing, est diffusée sur internet. 
Le musée, couvrant une superficie de 3000 mètres carrés, sera composé de six salles. La première sera dédiée aux anciennes traces de civilisation découvertes à Yunyang, la deuxième aux vestiges archéologiques excavés localement datant du début de notre ère, attribués au peuple ba, et la troisième aux deux millénaires d'histoire locale de production de sel. La quatrième sera consacrée à la plus ancienne ville établie dans les TroisGorges, Quren, implantée sur le territoire de Yunyang dès le début de notre ère. La cinquième portera sur une révolte procommuniste locale survenue en 1935, et la dernière sur le yimin des Trois-Gorges à Yunyang.

Le centre culturel fut inauguré en juin 2012 et le musée, en septembre de la même année (SOY 2012b). Comme dans tous les musées d'État depuis 2008, l'entrée sera gratuite. Une nouvelle section du bureau de la culture a été créée spécifiquement pour administrer cette institution. Ses membres ont suivi des formations auprès des muséographes du musée des Trois-Gorges.

\section{Du sens attribué à l'architecture muséale}

La différence manifeste entre ces deux projets muséaux apparaît dans l'ambition dont ils témoignent. Le parc muséographique soutenu par Xiao Min est affiché comme une initiative d'envergure régionale alors que le musée réalisé sous la direction de Li Hongyi est clairement présenté comme une institution locale.

\section{Un projet «régionaliste»}

Xiao Min et le bureau local de la culture des années 2002-2008 souhaitaient proposer une exposition portant sur les déplacements tels qu'ils se sont déroulés dans l'ensemble du réservoir du barrage des Trois-Gorges. II était aussi question de rendre compte des précédents mouvements de population ayant traversé ce territoire. De manière générale, le programme accordait une grande place à la culture des Trois-Gorges. II incluait un palais des arts et traditions populaires, qui présenterait des expositions culturelles et artistiques, ainsi qu'une scène d'opéra pour accueillir des représentations en dialecte régional. Des boutiques devaient proposer des produits considérés comme spécifiques aux Trois-Gorges et le programme prévoyait que l'architecture des bâtiments du parc muséographique soit propre à ce lieu.

La culture de Chongqing constituait également un axe thématique important. Le parc muséographique devait, selon le programme officiel, révéler la tradition culturelle de Ba-Yu (巴渝), toponyme constitué de caractères faisant référence à la région. $\mathrm{Au} \mathrm{v{ } ^ { e }}$ siècle, la ville de Chongqing portait le nom de Yuzhou, en référence à la rivière Yu, aujourd'hui appelée fleuve Jialing, un affluent du Yangzi Jiang traversant la cité. Bien qu'elle soit nommée Chongqing depuis 1189, la dénomination Yuzhou est encore largement employée. Au fil des siècles, le terme «Yu» en vint à désigner la région entourant cette ville. Le caractère «Ba» désigne quant à lui un espace non clairement délimité, correspondant en partie à la municipalité de Chongqing. II fait référence à un ancien royaume du même nom, force politique importante dans la région, du ville siècle jusqu'à sa chute en 316 avant notre ère (Kleeman 1998: 26-37). En 2007, le directeur du bureau de la protection des vestiges de Yunyang m'a informée que la construction
9. Cette somme correspond à environ 13 millions d'euros.

10. Une fonctionnaire du bureau de la protection des vestiges me fit rencontrer Li Jianjun, qui accepta de me parler du musée. Intéressé par mon projet d'article sur les institutions muséales de la région, il me reçut à plusieurs reprises et organisa une visite du site. 
11. C'est au cours de la VIII ${ }^{\circledR}$ session de l'Assemblée nationale populaire, en 1997 que la décision de créer cette nouvelle entité administrée par le gouvernement central fut entérinée. Elle s'étend sur une superficie de 82400 kilomètres carrés, rassemble une quarantaine de districts et compte plus de 32 millions d'habitants (Padovani 2004: 10). Cette décision fut notamment liée à la création du réservoir des Trois-Gorges. Elle devait permettre de gérer plus étroitement le processus de déplacement et de reconstruction, mais aussi de limiter le pouvoir de la puissante province du Sichuan, dont les responsables régionaux avaient manifesté leur opposition au barrage.

12. Le directeur du bureau de la protection des vestiges de l'époque me raconta sa participation aux fouilles archéologiques, dont les vestiges excavés seront exposés dans le musée de Yunyang. du portail d'entrée du parc muséographique s'inspirerait des récentes découvertes archéologiques locales sur l'architecture de cette époque. Cette année-là, plusieurs entreprises d'architecture avaient répondu à l'appel d'offres, mais aucun des projets, jugés «trop modernes», n'avait été retenu.

La culture Ba-Yu devait également apparaitre dans le parc muséographique à travers des représentations artistiques, les mêmes qui ont été chaque année proposées aux habitants lors de la fête instaurée par Xiao Min. Depuis une quinzaine d'années, ce thème est omniprésent à Chongqing. II fait l'objet d'expositions, de publications et de programmes télévisés. L'expression «Ba-Yu» était déjà employée par le passé, mais sa mobilisation récente par la rhétorique officielle régionale ne peut être dissociée de la création de la municipalité autonome de Chongqing en 1997. La ville de Chongqing ainsi que trois ensembles régionaux (dont Yunyang) ont été séparés de la province du Sichuan et réunis pour former un vaste espace administratif ${ }^{\mathbf{1 1}}$. Les autorités régionales s'emparèrent du toponyme $\mathrm{Ba}$-Yu pour se doter d'une identité valorisée, soulignant la cohérence historique et culturelle du nouveau territoire.

En choisissant la culture Ba-Yu pour axe thématique du parc muséographique, les autorités de Yunyang suivaient la tendance de l'époque, tout en affirmant, sans doute, une sorte d'allégeance au nouveau gouvernement régional dont on attendait beaucoup (notamment des financements); sans oublier les effets de l'ambition politique de Xiao Min, qui visait un poste au gouvernement régional. L'équipe de fonctionnaires dont il s'était entouré lors de son mandat a peut-être aussi joué dans l'importance accordée à la culture régionale. Plusieurs d'entre eux étaient diplômés d'archéologie, d'histoire ou de littérature, et l'intérêt de certains pour la culture et l'histoire de leur région était manifeste ${ }^{\mathbf{1 2}}$.

\section{Des bâtiments muséaux comme métaphore de la topographie}

Dans le programme du musée de Yunyang qu'a fait réaliser Li Hongyi, la culture $\mathrm{Ba}-Y u$ semble en revanche avoir été totalement éclipsée. La seule référence à la région apparaît discrètement dans le discours sur l'architecture du nouveau complexe culturel. Celle-ci est présentée à la fois comme contemporaine et traditionnelle: «Nous avons cherché à unifier une forme historique ancienne et un langage architectural moderne. » (Tanghua Studio 2011)

La particularité du projet proposé par l'entreprise d'architecture Tanghua Studio réside dans son toit à un seul versant, fortement incliné, dont le bord nord, au sommet du bâtiment, rejoint le bord sud situé au niveau du sol, en bordure du fleuve. La façade du musée forme ainsi un triangle (fig.4). Le discours officiel annonce que ce toit penché apporte au bâtiment un «esprit régional» (地域精神, diyu jingshen) [SOY 2012a]. En effet, selon plusieurs membres du bureau de la culture, les toits très pentus seraient caractéristiques de l'architecture locale, liés à la forte pluviométrie que connaît la région. Toutefois, la même forme est observable ailleurs en Chine. L'architecture globale du bâtiment, représentant le 
paysage montagneux des Trois-Gorges, constituerait une autre spécificité régionale. Ainsi, les habitants peuvent, depuis la base du toit au bord du fleuve, en gravir les innombrables marches pour rejoindre son sommet, de la même façon qu'ils gravissent chaque jour les collines de la région.

Cette manière d'envisager ce bâtiment comme une représentation métaphorique du paysage régional rappelle le discours sur la façade du musée des Trois-Gorges construit à Chongqing en 2005. Selon le site internet de ce musée, la structure externe du bâtiment «représente» (代表, daibiao) la topographie des lieux (fig.5). II est expliqué que l'arc courbé sur la façade représente le barrage, tandis que le large panneau en verre de couleur bleue symbolise l'eau qui y est concentrée. Le mur massif en grès incarnerait quant à lui les montagnes. Le site indique que «l'ensemble reflète la caractéristique du paysage des villes de Chongqing". Le barrage et l'élévation forcée des eaux sont ici en osmose avec l'environnement régional.

\section{Un projet, reflet de la culture chinoise, pour mettre en ordre le monde local}

Bien que cette spécificité architecturale d'évocation de la topographie régionale soit mentionnée par les autorités locales lorsqu'elles communiquent sur le centre culturel, elle n'est pas mise en avant, pas plus qu'elle n'est commentée dans les médias. Tous soulignent que «l'ensemble de sa structure est inspiré du symbole culturel traditionnel chinois dit du “quadrillage des neuf palais” (九宮格, jiugongge)» [SOY 2012a; Xu 2012]. (fig.6) II s'agit d'une figure géométrique constituée d'un cadre de forme carrée subdivisé en neuf carrés de taille égale. Le toit du centre culturel a en effet l'apparence d'un tel quadrillage. Tanghua Studio (2011) suggère également que l'agencement interne de multiples unités sur cinq étages constitue une sorte de quadrillage complexifié en trois dimensions.

Le jiugongge fait référence à la structure de base employée en calligraphie pour un tracé bien proportionné des caractères chinois, ainsi qu'à celle qui sert au carroyage des terres (Hu-Sterk 2004: 177). Selon Mark Edward Lewis (2006b), cette technique particulière appliquée dans la division des champs en neuf parcelles carrées égales est l'une des plus anciennes de la Chine impériale. Nommée système du «puits» (井, jing), elle est attribuée aux Zhou (qui ont régné du $\mathrm{Xl}^{\mathrm{e}} \mathrm{au} \mathrm{II}^{\mathrm{e}}$ siècle avant notre ère) et «découle de l'idée que la division est la base de l'ordre social et du bon gouvernement" (ibid. : 248). Lewis (ibid. : 50) montre que ce quadrillage a été par la suite adopté comme modèle du monde. Établi à la fin de la dynastie des Zhou, le mythe de Yu le Grand, fondateur de la première dynastie (légendaire) chinoise, rapporte qu'après avoir vaincu les inondations, ce démiurge sillonna l'espace pour fixer les frontières et diviser le territoire du monde connu en neuf provinces délimitées par les hautes montagnes et les grandes rivières, ce qui lui permit d'ordonner l'univers et de le stabiliser. Pour Lewis (2006a: 30-32), qui restitue ce récit, le neuf constitue dans la pensée chinoise un chiffre magique renvoyant à l'idée de totalité. Le quadrillage des neuf palais représente une telle unité complète et ordonnée.

Les architectes du centre culturel soulignent que cette forme «est un ancien motif chinois de structure véhiculant une profonde significa-

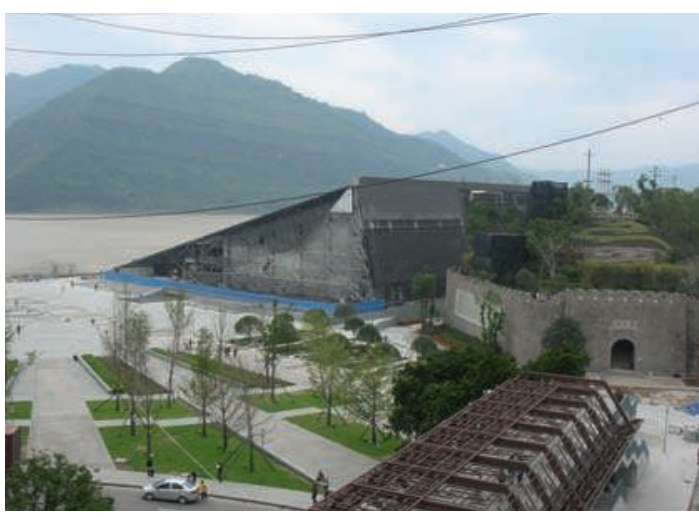

fig. 4

Le toit à un seul versant et la façade du musée de Yunyang Photo Katiana Le Mentec.

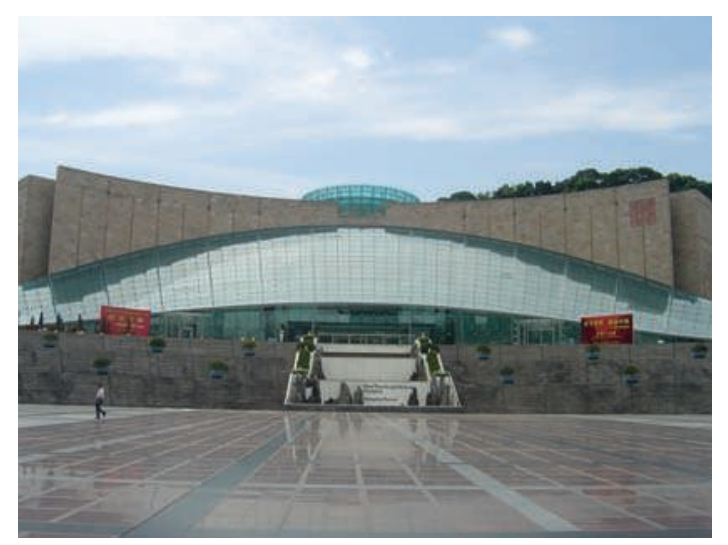

fig. 5

Façade du musée des Trois-Gorges à Chongqing.

Photo Katiana Le Mentec.

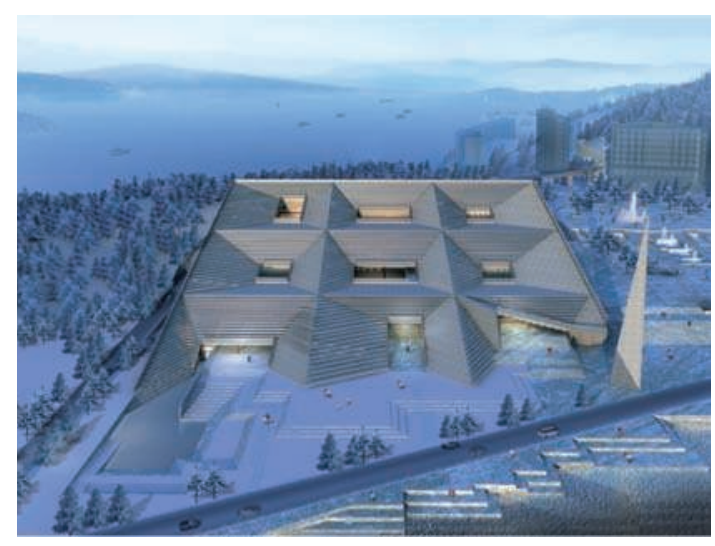

fig. 6

Le toit du centre culturel de Yunyang: la structure est inspirée du symbole traditionnel chinois dit du "quadrillage des neuf palais " 


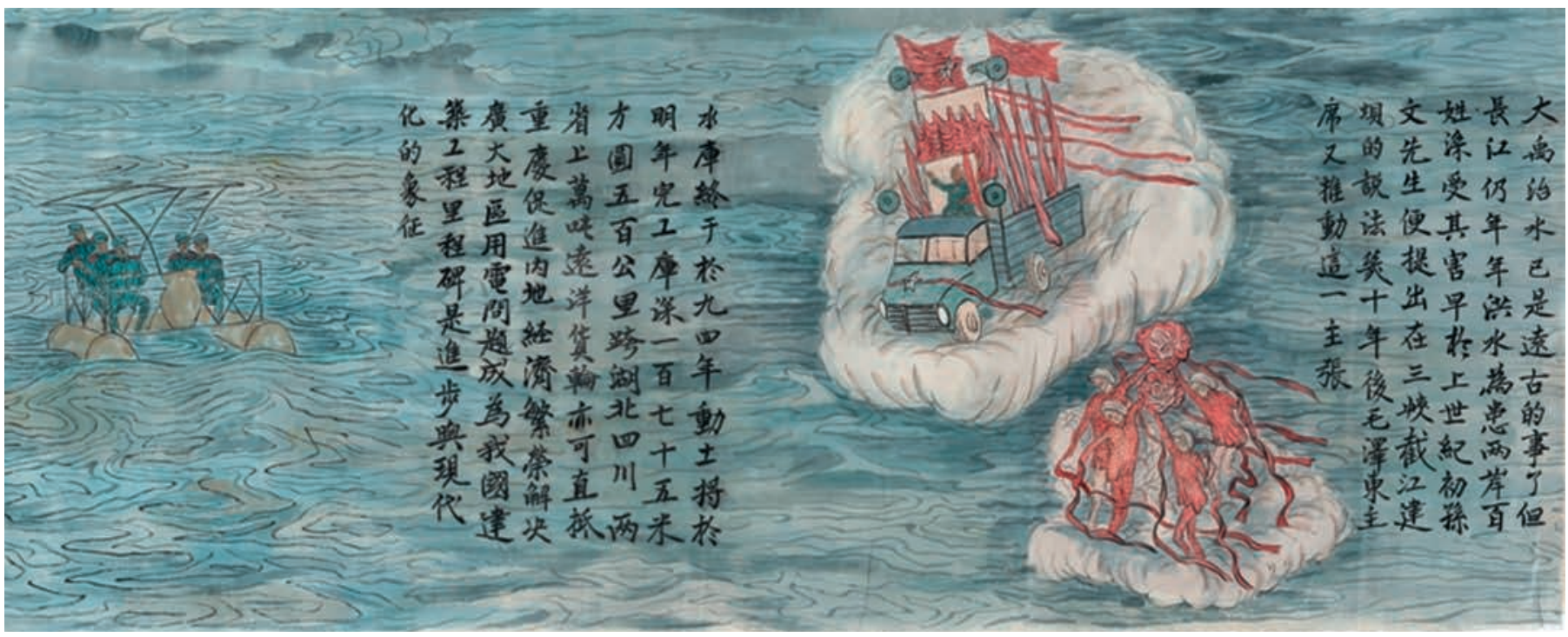

fig. 7

Ji Yunfei, Les Migrants des Trois-Gorges (détail), 2009, avec l'aimable autorisation de l'artiste et de la galerie James Cohan.

Le texte dit ceci:

Le mythe de Yu le Grand maîtrisant les eaux est déjà ancien, et pourtant, chaque année les crues du long fleuve font terriblement souffrir les habitants des deux rives.

Au début du siècle dernier. l'honorable Sun Yat-sen proposa de séparer les eaux du fleuve en construisant un barrage au niveau des Trois-Gorges. Quelques décennies plus tard, le président Mao Zedong promut à nouveau cette idée.

Il aura fallu quatre-vingt quatorze ans pour que le réservoir du barrage voit le jour. L'an prochain, les eaux monteront jusqu'à cent soixante-quinze mètres au-dessus du niveau de la mer. Le fleuve se déploiera sur près de cinq cent kilomètres et traversera deux provinces: le Sichuan et le Hubei.
Les cargos chargés de plus de dix milles tonnes pourront atteindre Chongqing.

La prospérité économique de l'arrière pays sera accélérée.

Le dilemme de l'équipement en électricité d'un vaste territoire sera résolu.

Cette oeuvre d'ingénierie deviendra la marque nationale et le symbole du progrès et de la modernisation du pays. tion philosophique et religieuse. II fut largement employé en architecture en raison de la stabilité et du sens de l'ordre qu'il représente. » (Tanghua Studio, 2011) La référence à la «stabilité» (平穩性, pingwenxing) et à «l'ordre» (秩序, zhixu) pour décrire la symbolique architecturale d'un établissement institutionnel tel que le complexe culturel de Yunyang n'est pas anodine. Les travaux de Chen Qi (2009), Wang Zhiyuan et Li Jizun (2009) montrent que la configuration des neuf palais fait l'objet d'un certain intérêt dans le domaine de l'architecture en Chine aujourd'hui. Le toit du pavillon national de l'Exposition universelle à Shanghai en 2010 a par exemple été construit sur ce modèle; une forme qui implique un «ancrage cosmologique » de l'édifice au centre du monde et renvoie à un «nouvel ordonnancement du monde " (Névot, à paraître). À Yunyang, ce choix architectural pour le centre culturel renvoie à une volonté similaire de représenter, pour l'actualiser et le renforcer, le pouvoir politique en tant qu'il met en ordre le monde. Les dirigeants ont certainement jugé cette opération symbolique opportune après les nombreux bouleversements (topographiques, sociaux, administratifs, écologiques) provoqués localement par la création du barrage.

L'ancienneté et la spécificité chinoises du jiugongge sont signalées tant par les médias que par les autorités locales. Pour les architectes du centre culturel, le choix de cette forme est l'occasion de «rendre hommage à l'esprit éternel de la tradition et de l'histoire [chinoises] » (Tanghua Studio 2011). Ils ne mentionnent pas le mythe de Yu le Grand mais glosent autour d'une citation du Rituel des Zhou ${ }^{13}$ extraite du chapitre "Mémoires sur les manufactures». Celle-ci fait référence à cette forme particulière de division de l'espace que les artisans constructeurs donnaient aux campements. En choisissant ce quadrillage pour le centre culturel et en soulignant explicitement son lien aux Zhou, le gouvernement de Yunyang fait ainsi entrer le district dans la postérité culturelle de l'antique civilisation chinoise. Non seulement le Rituel des Zhou est une référence nationale, mais leur dynastie s'est développée à partir du bassin du fleuve Jaune, que l'historiographie nationale a toujours considéré comme seul et unique berceau de la civilisation chinoise. Ce choix architectural est à l'opposé de celui effectué 
par Xiao Min et son équipe pour le parc muséographique, mettant en avant I'histoire et la culture régionale de Ba-Yu.

Dans le complexe culturel de Yunyang, le rattachement du district au «centre» n'est pas seulement signifié par la référence au système de pensée hérité des Zhou. La salle du musée dédiée à la révolte populaire locale survenue en 1935 rappelle l'engagement, avant l'heure, de la population locale pour le parti arrivé au pouvoir en 1949. Cet épisode ne constitue pas un événement marquant pour les habitants, mais il est mentionné dans I'historiographie officielle. Cette manière d'affirmer au sein d'un musée et à travers un épisode local la loyauté du peuple au Parti est classique en Chine, mais elle était absente du programme soutenu par Xiao Min. Celui-ci prévoyait plutôt de mettre en scène la force et l'efficacité du pouvoir en place - tant local que national - dans la gestion des déplacements.

Li Hongyi a donc fait le choix d'une référence au "centre " et à la dynastie des Zhou. Cette décision est-elle liée au fait qu'il est originaire de la province du Shandong, particulièrement proche de Pékin et territoire de l'ancien royaume des Zhou? Ce choix a pu être guidé à la fois par ses références culturelles et par sa volonté de réaffirmer son allégeance au pouvoir central. II n'a été muté que temporairement dans cette région montagneuse et il serait surprenant qu'il prévoie d'y faire carrière. Cet exemple de mesure de politique culturelle illustre la manière dont la présence d'un «étranger » au sommet d'une administration locale permet d'y imposer une vision nationale. II peut s'agir d'une conséquence attendue (voire exigée) des autorités centrales ayant instauré ce système de jumelage entre circonscriptions. Dans le système impérial, le principe de mutation de fonctionnaires en dehors de leur province natale était généralisé. II constituait pour le pouvoir national une manière de limiter le régionalisme, d'être davantage informé, d'imposer sa politique et de mieux contrôler ce qui se passait au plan local, en particulier dans les territoires éloignés du centre.

La décision de Li Hongyi ne semble toutefois guère susciter l'enthousiasme général. Lors de la visite du site, un responsable du musée a souligné que cette forme ne lui plaisait pas: elle est «trop moderne», il aurait «préféré une architecture s'inspirant de la culture Ba». Ce fonctionnaire manifeste-t-il par là son sentiment d'appartenance à la région, plus fort que celui le liant au pays?

\section{De la mise en scène et en récit du déplacement forcé}

La question du yimin des Trois-Gorges était au cœur du projet de parc muséographique soutenu par Xiao Min. La rue et la place principales du parc devaient être nommées «du yimin»; un vaste musée entièrement dédié à ce thème et une bibliothèque rassemblant des ouvrages sur le sujet étaient prévus. II ne s'agissait pas seulement de présenter les déplacements de population et le processus de reconstruction des villes provoqués par la création du barrage. Le yimin se rapportait en l'occurrence à l'ensemble des mouvements de population survenus dans cette région au cours des trois derniers millénaires. Il était question d'exposer et d'enseigner la «culture du yimin ». Ce concept a été inventé par Xiao Min, qui l'a présenté en 2002 lors d'une réunion officielle à Yunyang (SOY 2010). Il proposait de considérer le
13. Ce livre est l'un des trois ouvrages classiques du confucianisme. Pour Kristofer Schipper (1998: 824), il décrit l'organisation de l'État féodal des Zhou et «fut écrit sous les Han pour servir d'illustration aux théories confucianistes de cette époque au sujet du parfait gouvernement». 
yimin comme une spécificité historique et culturelle de la région des TroisGorges. Les déplacements de population, quels qu'ils soient, constituent un phénomène régulier aussi bien dans l'histoire régionale que dans celle de la Chine. L'adoption de cette perspective sur l'histoire locale, axée sur le contexte migratoire, permettait aux autorités de dédramatiser et de justifier le déplacement de population provoqué à Yunyang par la création du barrage des Trois-Gorges.

Avec ce concept, Xiao Min souhaitait aussi donner une particularité, un label, au district. Les autorités locales présentaient celui-ci comme étant le plus touché par le processus du yimin dans les Trois-Gorges. Le plan local de développement identifiait la culture du yimin comme la nouvelle ressource touristique fondamentale du district. Lorsqu'il y a construction de barrages, les réservoirs, apportant prestige et renommée, servent parfois à alimenter le discours identitaire régional ou local tout en devenant une ressource économique grâce à l'exploitation touristique des sites (Wateau 1999, 2004; Revet 2007 : 249-261). À Yunyang, le yimin joue un rôle équivalent.

En 2005, les autorités régionales ont validé cette proposition et encouragé le gouvernement local à promouvoir et enseigner au peuple ce nouveau concept (SOY 2010). Pour ce faire, Xiao Min s'est appuyé sur les projets culturels du parc muséographique et de la fête locale, tous deux nommés «de la culture du yimin des Trois-Gorges» et ouvertement envisagés comme des plateformes privilégiées dites d'expression, de mise en ordre et de diffusion de cette conception particulière (Li 2006). Dans le parc muséographique, les ouvrages de la bibliothèque et les expositions devaient évoquer des mouvements de population fort divers: les pérégrinations mythiques du peuple ba guidé par son chef Linjun (Kleeman 1998: 118119), les annexions militaires telle celle des Qin au Iv ${ }^{e}$ siècle avant notre ère, les innombrables transferts de population exigés par les empires Ming et Qing (entre 1368 et 1911) dans le cadre de politiques de repeuplement du Sichuan, les fuites de réfugiés (dont l'installation dans la région est définitive ou temporaire, comme au cours de la seconde guerre mondiale) ou encore les migrations de familles pauvres. Dans le discours officiel local, tous ces phénomènes sont considérés comme les facettes d'un même processus appelé yimin (SOY 2010). Cette rhétorique est permise par la plasticité de ce terme, dont la définition est large et qui peut référer tant aux circulations volontaires ou forcées qu'aux mouvements venant de ou allant vers l'extérieur ${ }^{14}$.

L'idée qu'il existe une culture historique, propre aux Trois-Gorges et fondée sur l'expérience du yimin, a fait l'objet d'une importante médiatisation régionale. Ce discours a été rapidement repris par la municipalité de Chongqing, dont les autorités cherchent autant à légitimer le déplacement de population qu'à élaborer les fondements d'une identité propre. Au fil des ans, les références à ce thème se sont multipliées par le biais d'ouvrages, de poèmes, de romans, d'articles ou encore d'activités culturelles (lectures publiques, spectacles de théâtre, de danse et de chant). Une nouvelle série télévisée portant sur l'histoire des yimin survenus dans la région de Chongqing a été produite. Un petit musée sur le sujet a également été ouvert au sein 
de la guilde du Huguang, établie il y a deux siècles à Chongqing par des migrants venus de l'est des gorges. La protection d'anciennes guildes de migrants constitue d'ailleurs une action patrimoniale préconisée par un article publié dans le journal régional du Parti communiste (Yu 2007). Selon Xiao Min, Chongqing s'apprêterait à instaurer la fête de la culture du yimin de la ville. Les chercheurs se sont aussi intéressés à ce concept en proposant des conférences et des publications ${ }^{15}$.

Cette récupération par l'administration régionale pourrait être à l'origine de l'effacement du thème de la culture du yimin dans le nouveau projet muséal de Yunyang. D’après le programme, la salle dédiée au yimin des Trois-Gorges présentera le barrage (du processus décisionnel à sa réalisation) et le processus de déplacement à l'intérieur comme à l'extérieur du district: de l'annonce officielle au suivi de l'installation des habitants en incluant les conditions, les étapes de la gestion par le gouvernement local et la supervision par les officiels de Pékin, aussi bien que des cas particuliers de fonctionnaires en charge et de familles déplacées.

Le concept de culture du yimin a-t-il aussi été mis de côté par la nouvelle équipe gouvernementale en raison du peu d'écho qu'il a eu parmi la population locale? Cette éviction est-elle liée à son association à l'ancien gouverneur dont les autorités actuelles cherchent à se démarquer? Ces deux hypothèses ne semblent pas se vérifier puisqu'un autre concept créé par Xiao Min et ayant tout aussi peu été repris par la population est très largement mobilisé dans le projet soutenu par Li Hongyi: celui d'« esprit du yimin ».

\section{Commémorer le yimin des Trois-Gorges et l'esprit patriotique de la population}

L'«esprit du yimin» (移民精神, yimin jingshen) sera l'un des axes thématiques de la salle dédiée au yimin des Trois-Gorges du musée de Yunyang, conformément aux projets culturels proposés par Xiao Min. Ce dernier a présenté ce concept pour la première fois en 1999, avant celui de culture du yimin, alors qu'il était secrétaire adjoint du Parti communiste à Yunyang (SOY 2010). L'esprit du yimin représente un modèle idéaltypique des qualités qui sont exigées des habitants par l'État dans le cadre de la construction du barrage des Trois-Gorges. En 2006, lors du discours inaugural de la fête de la culture du yimin, Liu Zuli, secrétaire du Parti communiste de Yunyang, le présenta comme «la sublimation, dans l'éternité, du patriotisme, de la dévotion, de la coopération et de la lutte». Le discours officiel chinois fait très largement appel à la rhétorique de la guerre et du sacrifice lorsqu'il est question des conséquences de l'édification du barrage des Trois-Gorges. La mise en pratique de cet esprit est présentée comme un devoir civique, voire filial, l'État et le Parti étant décrits comme des substituts à la famille - une rhétorique classique dans le discours de propagande communiste. On encourage la population à «incorporer» cet esprit. Employée chez les philosophes chinois dès l'Antiquité pour désigner l'idée même de la vie, la notion chinoise de jingshen («esprit»), signifiant une essence animant les êtres qui doivent perpétuellement l'entretenir, convient particulièrement bien à la rhétorique officielle. L'esprit du yimin est parfois présenté comme révélé par le barrage des Trois-Gorges, émergeant
14. Le choix d'envisager sans distinction toutes sortes de déplacements de population est également celui de chercheurs chinois te Ge Jianxiong ([éd.] 1997, 2002) directeur du département d'histoire de la très renommée université Fudan (Shanghai) et spécialiste du yimin. Bien que ce parti pris soit critiqué par des historiens comme Meng Yanhong (2001), de l'académie des sciences sociales de Pékin, qui reproche l'absence de définition stricte du terme yimin, il est repris par des chercheurs occidentaux tel Pál Nyíri (2010), qui ne mentionne pas les limites du traitement conjoint de ces différentes formes de mobilité.

15. Pour le professeu Xiong Jianli, directeur du département du yimin à l'Institut d'études des Trois-Gorges, la culture régionale est le produit du mélange de cultures et d'influences issues de différentes vagues de yimin. Selon lui, le yimin provoqué par le projet des Trois-Gorges " a enrichi et développé la culture [des Trois-Gorges] " (Xiong 2007). Sun Shangi et Yang Yaojian (2004 : 24-27) rapportent quant à eux que "Chongqing est une municipalité du yimin [et que] le yimin a composé la culture historique de Chongqing ". 
16. Pour l'analyse du discours portant sur le sacrifice des yimin, voir Le Mentec (2011: 119-130).

17. Ces bâtiments, lieux de mémoire et de culte du district, ont été replacés dans le parc grâce au fonds de protection des vestiges financé par le projet hydroélectrique des Trois-Gorges. naturellement chez les habitants à travers l'expérience actuelle et passée du yimin. Selon le point de vue officiel, repris par certains chercheurs (Xiong 2007), la région a connu tant de déplacements de population que la bravoure et la dévotion envers le bien commun sont devenues une spécificité du tempérament local, prenant forme dans l'esprit du yimin.

Pour le gouvernement local, le musée de Yunyang devra, tout comme devait le faire le parc muséographique, «transmettre et exalter» l'esprit du yimin. Les visiteurs sont censés être touchés par l'acte dit d'abnégation des familles déplacées. La série de photographies reproduite dans le programme du nouveau musée montre des personnes en pleurs, affligées de devoir quitter leur pays natal et de se séparer de leur famille. Les légendes reprennent des slogans sur la douleur et le cœur serré des yimin (personnes déplacées). Leurs actions sont identifiées à un sacrifice (鈞牲, xisheng) au nom du peuple et du pays ${ }^{\mathbf{1 6}}$. Les habitants de Yunyang sont aujourd'hui familiers de ces images, diffusées localement depuis plusieurs années, et de la rhétorique qui les accompagne. Les mêmes motifs étaient présents dans l'exposition itinérante inaugurée au musée des Trois-Gorges en 2006, intitulée Un million de yimin émeuvent la Chine: ode à l'esprit du yimin des Trois-Gorges. Ce musée comporte d'ailleurs une salle présentant le barrage et ses conséquences, au milieu de laquelle trône un prix décerné en 2002 par la chaîne de télévision publique chinoise aux yimin des Trois-Gorges, qui ont su émouvoir la Chine.

Au musée de Yunyang, les cas exemplaires du paysan Ran Yikui (ayant perdu l'intégralité de ses arbres fruitiers) et de trois fonctionnaires locaux ayant fait preuve de désintéressement et de renoncement illustreront l'esprit du yimin. L'un de ces fonctionnaires serait décédé des suites d'un cancer faute d'avoir pris soin de lui pendant sa mission de gestion des déplacements. Des poèmes louant les exploits des yimin, parmi lesquels une poésie de Xiao Min qui a en accepté la reproduction, seront gravés sur des stèles.

Comme le prévoyait initialement le projet du parc muséographique, le musée de Yunyang intégrera un monument commémorant les habitants déplacés ayant fait preuve de l'esprit du yimin. Dans le parc, le portail d'entrée ainsi qu'une pagode devaient être dédiés à la mémoire de «ceux qui ont souffert ». Dans le but de commémorer les yimin, Xiao Min avait aussi prévu la construction soit d'un temple des ancêtres dédié aux clans familiaux yimin des Trois-Gorges, soit d'une galerie de stèles portant les noms des habitants installés en dehors des Trois-Gorges. La visite du musée de Yunyang se conclura quant à elle sur un «monument commémoratif», un mur gravé en relief intitulé «ode à l'esprit du yimin».

\section{Entre présent et passé, modernité et tradition}

À Yunyang, les projets muséaux soutenus par les équipes gouvernementales successives se sont vu fixer plusieurs objectifs. L'un d'eux est de refléter les particularités locales tout en signifiant le rattachement culturel et historique du district à un ensemble plus vaste, régional ou national. Un autre concerne la diffusion d'un discours pédagogique, d'une interprétation officielle donnée aux conséquences du barrage des Trois-Gorges qui 


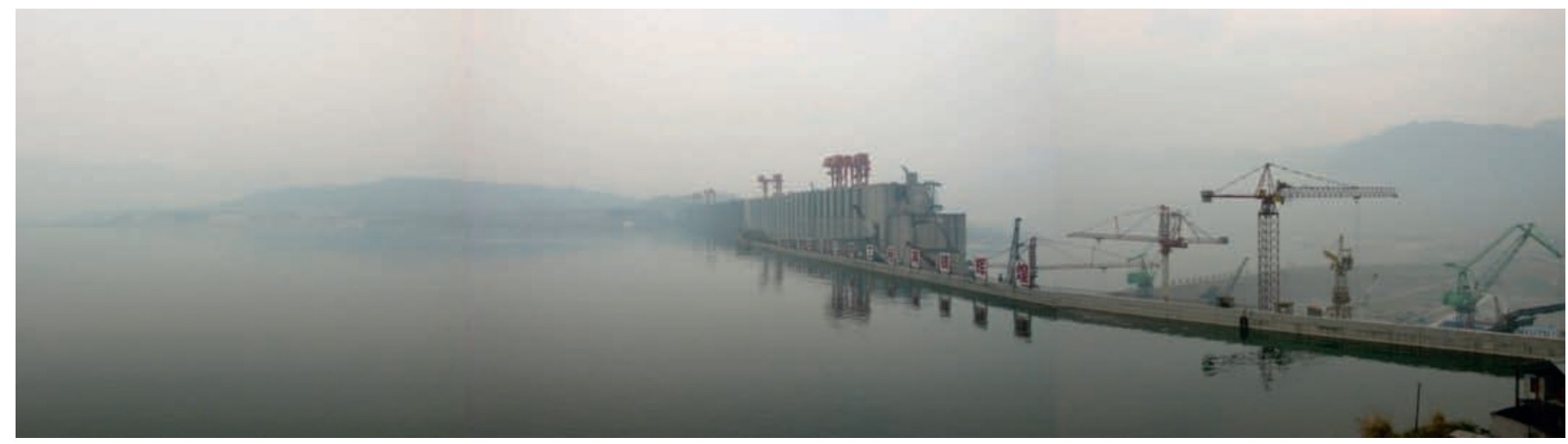

légitime les bouleversements. Se servir du passé pour parler d'événements actuels, pratique observée dans de nombreux musées de par le monde, est ici manifeste. Ces projets locaux constituent également des plateformes permettant aux fonctionnaires d'élaborer interprétations et concepts qui reflètent aussi un certain nombre d'enjeux aux différents niveaux de la hiérarchie administrative.

Je souhaiterais conclure sur la volonté locale émanant de ces projets muséaux d'unir le passé au présent, de créer une réalité mêlant harmonieusement tradition et modernité. Ceux-ci transmettent l'idée que, malgré les bouleversements (transformations topographiques, éclatement des réseaux familiaux et sociaux, immersions de tombes, de lieux de culte et de mémoire), le passé, les traditions, le lien aux ancêtres ou les sites immergés n'ont pas été perdus. Ce point de vue apparaît dans le discours sur l'architecture du complexe culturel ainsi que dans ceux portant sur la culture du yimin et l'esprit - censé être hérité des ancêtres - qui lui est attaché. Il est également mis en évidence à travers l'importance que ces projets muséaux accordent à l'ancienne et à la nouvelle écologie. Le programme du parc muséographique intégrait un jardin écologique au sein duquel des paysages immergés devaient être reproduits en miniature. Xiao Min avait déjà fait déplacer des arbres centenaires des collines entourant l'ancien chef-lieu - où se trouvaient les tombes des proches des résidents - pour les installer dans le parc longeant la berge. Des rochers dont la forme a été façonnée au fil des millénaires par le courant tumultueux du fleuve, transformé en «lac paisible», y avaient également été disposés. Un journaliste écrivait au sujet du parc muséographique qu'il permettrait aux personnes déplacées de «conserver un espace pour retrouver leurs racines et visiter leurs ancêtres» (Ji 2008). Bien que le projet muséal de Xiao Min n'ait pas été réalisé, de tels espaces sont aujourd'hui proposés aux habitants du nouveau chef-lieu avec le parc le long de la berge présentant ces arbres et ces rochers, et le «parc patrimonial» (文物園, wenwuyuan) accueillant des vestiges délocalisés, inauguré en 2009 au sommet de la colline 17. Dans le musée de Yunyang, le paysage local constitue également l'un des thèmes de la salle dédiée au yimin des Trois-Gorges. Le programme accorde une certaine importance aux anciens lieux de vie, ruraux et urbains, qui seront exposés par le biais de photographies panoramiques. Cette façon de les reproduire par différentes méthodes complémentaires au sein d'espaces muséaux et culturels est une manière, pour les autorités locales, d'en dédramatiser la perte et de fig. 8

La construction du barrage des Trois-Gorges à Yichang (Hubei), 2004

(C) Peter van Agtmael/ Magnum Photos. 
récupérer les repères territoriaux de la population afin de les insérer dans les nouveaux lieux de vie.

À travers leur rhétorique et leurs mesures de politique culturelle, les autorités de Yunyang cherchent à façonner un monde renouvelé qui conserve la richesse, la beauté ainsi que les références efficaces à l'ancien monde précédant l'immersion. Dans ce but, elles ont élaboré un autre concept, celui de «paysage du yimin» (移民場景, yimin changjing), renvoyant à la topographie transformée qui serait imprégnée de l'ancienne. Le concept de «ville yimin », associé au nouveau chef-lieu, désigne de la même manière une ville moderne, marquée par une multitude de références au passé. La dernière salle du musée proposera un aperçu de ces lieux du yimin en exposant des prises de vue anciennes et récentes. C'est précisément cette réalité, mêlant passé et présent, tradition et modernité, qu'est censée refléter l'architecture du centre culturel de Yunyang, métaphore de l'écologie locale. 


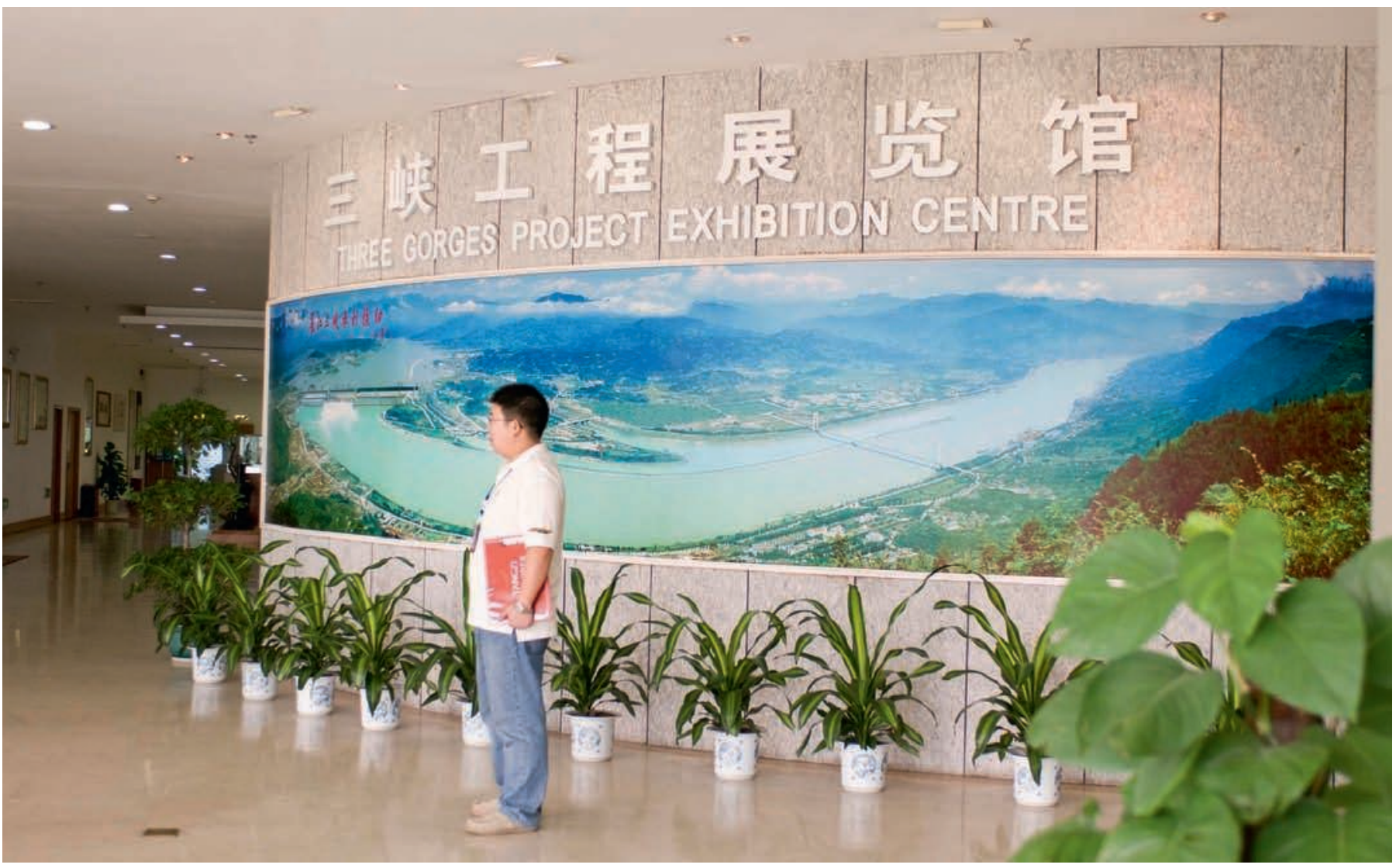

fig. 9

Salle d'exposition du projet des Trois-Gorges située dans la zone touristique du barrage, à Yichang (Hubei) (c) Marshall Segal. 


\section{Chen, Qi}

2009 « On the application of traditional Chinese cultural symbols of landscape architecture in modern design ", in IEEE International Conference on Computer-Aided Industrial Design \& Conceptual Design, Wenzhou, 26-29 novembre 2009. Hangzhou, China Academy of Art: 267-272.

\section{Ge, Jianxiong (葛剑雄)}

2002 «Le yimin des Trois-Gorges n'est pas le yimin à plus grande échelle dans l'histoire de la Chine" (三峡移民不是中国历史上最大 规模的移民. Sanxiayimin bushi zhongguo lishishang zuida guimo de yimin), site de l'université de Fudan (Shanghai), 1er juin; http://www.rwfd.fudan.edu.cn xueshu/zhuanjia/saxia.htm (consulté le 26 juin 2012).

\section{Ge, Jianxiong (葛剑雄) \\ [éd.]}

1997 L'Histoire du yimin en Chine (中国移民史, Zhongguo yimin shi), 6 vol. Fuzhou, Fujian Renmin Chubanshe.

\section{Hu-Sterk, Florence}

2004 La Beauté autrement. Introduction à l'esthétique chinoise. Paris, You-Feng.

\section{Ji, Wenling (纪文伶)}

2008 «La première ville yimin écologique de Chine vous invite à venir vous y installer » (中国第 一座生态移民城邀您来定居, Zhongguo diyi shengtai yimin cheng yaonin lai dingju), site du Journal économique de Chongqing (重庆商报, Chongqing Shangbao), 9 novembre; http://news.sohu. com/20070409/n249288749.shtml (consulté le 26 juin 2012).

\section{Kleeman, Terry}

1998 The Great Perfection. Religion and Ethnicity in a Chinese Millennial Kingdom. Honolulu, University of Hawai'i Press.

\section{Le Mentec, Katiana}

2011 Vivre le bouleversement du barrage des Trois-Gorges. Etude ethnologique des outils d'interprétation et des processus de résilience, thèse de doctorat de l'université de Paris-Ouest, sous la direction de Brigitte Baptandier.

\section{Lewis, Mark Edward}

2006a The Flood Myths of Early China. New York, State University of New York Press.

2006b The Construction of Space in Early China. New York State University of New York Press.

\section{Li, Dexiang}

2006 «Le projet du parc muséographique du yimin des Trois-Gorges ” (三峡移民博 物馆项目, Sanxiayiminbowuyuan xiangmu), site du gouvernement de Yunyang (www.yunyang.gov. cn), 13 avril; http://www.zj198.com/ gxyxproject/8528.html

(consulté le 26 juin 2012).

\section{Meng, Yanhong (孟彦弘)}

2001 "Questions sur les faits présentés dans l'ouvrage Histoire du yimin en Chine» (《中国移民史》 的史料及史实问题, “Zhongguo yiminshi » de shiliaoji shishi wenti), Recherches historiques (历史研究, Lishi yanjiu) 3;

http://ishare.iask.sina.com.cn/f/ 10301058.htm

(consulté le 26 juin 2012).

\section{Nanfengchuang}

2006 "Numéro spécial Yunyang ", Fenêtre du vent du Sud (南风窗, Nanfengchuang), journal publié par le Parti communiste de la ville de Canton (Guangdong), 21 mai.

\section{Névot, Aurélie}

À paraître La Couronne de l'Orient. Le centre du nouveau monde à Shanghai.

\section{Nyíri, Pál}

2010 Mobility and Cultural Authority in Contemporary China. Washington, The University of Washington Press.

\section{Padovani, Florence}

2004 "Les effets sociopolitiques des migrations forcées en Chine liées aux grands travaux hydrauliques. L'exemple du barrage des Trois-Gorges ", Les Études du CERI 103: 3-37.

\section{Revet, Sandrine}

2007 Anthropologie d'une catastrophe. Les coulées de boue de 1999 au Venezuela. Paris, Presses de la Sorbonne nouvelle.

\section{Schipper, Kristofer}

1998 "Zhouli», in Dictionnaire de la civilisation chinoise.

Paris, Encyclopædia Universalis Albin Michel : 824.

\section{SOY (Site internet officiel du district de Yunyang)}

2008 "Le parc muséographique du yimin des Trois-Gorges " (三峡移民博物园, Sanxia yimin bowuyuan), site du gouvernement de Yunyang, 15 juin 2008; cet article n'est plus disponible.

2010 «Exalter l'esprit du yimin et innover avec la culture du yimin " (弘扬移民精神与创新移民

文化, Hongyang yimin jingshen yu chuangxin yimin wenhua), site du gouvernement de Yunyang; http://yy.cq.gov.cn/yygk/ymwh (consulté le 26 juin 2012).

2012a «Présentation du Centre d'activités culturelles du peuple du district de Yunyang "

(云阳县市民文化活动中心简介, Yunyangxian shiminwenhuahuodong zhongxin jianjie), site du gouvernement de Yunyang, 5 mars:

http://www.yyjxw.gov.cn/xxzl/ ShowArticle.asp?ArticleID =61 (consulté le 26 juin 2012).

2012b «Le musée de Yunyang est officiellement inauguré ", (云阳博物馆正式开馆, Yunyang Bowuguan zhengshi kaiguan), site administré par le bureau de la propagande de Yunyang. 29 septembre 2012b-10-01 http://www.yyxw.net/ content/2012-09/29/ content_2532862.htm (consulté le 1 octobre 2012)

\section{Sun, Shanqi (孙善产) et Yang, Yaojian (杨耀健) [dir.] \\ 2004 Anecdotes et Contes de Ba-Yu (巴渝轶闻掌故 Bayu yiwen zhanggu). Chongqing, Chongqing Chubanshe.}




\section{Tanghua Studio}

2011 "Le centre d'activités du peuple du district de Yunyang » (云阳县市民活动中心, Yunyangxian shiminhuodongzhongxin), entreprise d'architecture Tanghua de Shenzhen, section du design (深圳市汤桦建筑师事务所设 计, Shenzhenshi Tanghua jianzhush shiwusuo sheji),

vidéo de 14 minutes 44

4 novembre; http://v.youku.com/v_ show/id XMzE5MzgyMDk2.html (consulté le 26 juin 2012).

Wang, Zhiyuan (王志遠) et Li, Jizun (李繼尊)

$\mathbf{2 0 0 9}$ Étude de l'architecture et de l'environnement intérieur au regard de la théorie du fengshui: l'exemple de la forme des neufs palais 建築與室內環境結合風水理 論之研究- 以理氣派九宮飛泊 法為例, Jianzhu yu shinei huanjing jiehe fengshui lilun zhi yanjiu -

Yili qipai jiugong feibo fa weili). Taipei, Association d'architecture de la République chinoise (中華民國建築學會,

Zhonghua Minguo Jianzhu xuehui), Société de publication des résultats des travaux d'architecture («Thèses ") [建築研究成果發表會論文集, Jianzhu yanjiu chengguo fabiao hui lunwen ji], 23 mai.

\section{Wateau, Fabienne}

1999 «Barrage, identités

et frontières ", in Juan Pujadas, Emma Martin, et Joaquim Pais de Brito (coord.), Globalización, Fronteras por Culturales y Políticas, y Ciudadanía, actes du viı ${ }^{\circledR}$ Congrès d'anthropologie, Saint-Jacquesde-Compostelle: 229-244.

2004 «De l'eau en Alentejo.

Marge, barrage et patrimonialisation ", Sud-Ouest européen 18: 54-58.

\section{Xiong, Jianli (熊建立)}

2007 «La culture des Trois-Gorges et la culture du yimin des Trois-Gorges" (三峡文化与三峡移民文化, Sanxia wenhua yu sanxia yimin wenhua), site du Centre d'information des Trois-Gorges, administré par China Telecom, branche de Wanzhou (Chongqing), 14 mars; cet article n'est plus disponible.
Xu, Zhiquan (徐志全)

2012 "Le centre d'activités

culturelles du peuple de Yunyang est achevé et mis en service" (云阳市民文化活动中心

建成并投人使用, Yunyang shiminwenhuahuodong zhongxin jiancheng bing touru shiyong), site internet du réseau médiatique des Trois-Gorges (三峡传媒网, sanxia chuanmei wang), basé à Wanzhou (Chongqing), 25 juin ; http://www.sxcm.net/news/ sx/2012-06/25/content_673050.htm (consulté le 25 juin 2012).

\section{Yu, Rongxin (俞荣新)}

2007 Déployer intensément la culture du yimin, promouvoir la marque culturelle de Chongqing, étudier les dix-sept esprits du Parti à prêcher au peuple (深人挖掘移民文化提升重庆文 化品位, 学习党的十七大精神宣 讲家, Shenru wajue yimin wenhua. Tisheng chongqing wenhua pinwei. Xuexi chang de shiqi da jongshen xuanjiangjia) Réfléchir et Appliquer, revue éditée par le parti communiste de Chongqing (Sikao yu yunyong, 思考与运用), 10, pp. 55-58.

\section{Zhou, Bin (周斌)}

2004 « Yunyang propose de construire le plus grand parc muséographique du yimin au sein de la zone du réservoir des Trois-Gorges " (云阳拟建三峡库 区最大的移民博物园, Yunyang ni jian sanxia kuqu zui da de yimin bowuyuan), site de la Three Gorges Corporation, 26 mars;

http://www.ctgpc.com.cn/news/ view_info.php?mNewsld=9489 (consulté le 27 juin 2012).

\section{Zhou, Yong (周勇) [dir.]}

2002 Histoire de Chongqing (重庆通史, Chongching tongshi). Chongqing, Chongqing Chubanshe.

ci-contre

Au bord du Yangzi Jiang avant l'immersion de la ville de Wanzhou (Chongqing), 2002 ○ lan Berry/Magnum Photos.

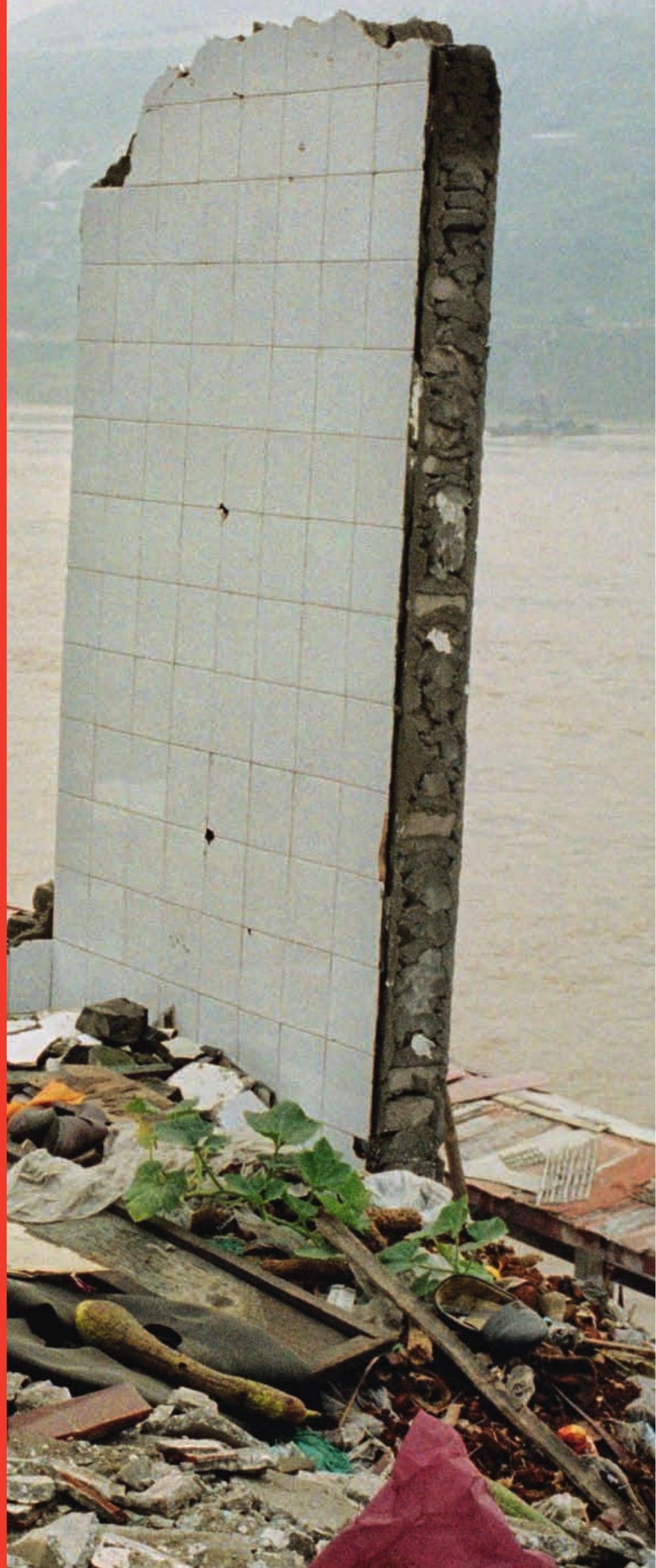

